\section{JTI}

JOURNAL OF

TRAUMA AND INJURY

Received: March 25, 2020

Revised: May 21, 2020

Accepted: June 2, 2020

\section{Correspondence to}

Pil Young Jung M.D., Ph.D.

Department of Surgery, Yonsei University Wonju College of Medicine, Regional

Trauma Center, Wonju Severance Christian Hospital, 20 Ilsan-ro, Wonju 26426, Korea

Tel: $+82-33-741-0573$

Fax: +82-33-741-0574

E-mail: surgery4trauma@yonsei.ac.kr

\title{
Hidden Hematologic Disease in Trau- ma Patients: A Report of Two Cases
}

\author{
Sung Woo Jang, M.D. ${ }^{1,2}$, Pil Young Jung, M.D., Ph.D. ${ }^{1,2}$ \\ ${ }^{1}$ Department of Surgery, Yonsei University Wonju College of Medicine, Wonju, Korea \\ ${ }^{2}$ Regional Trauma Center, Wonju Severance Christian Hospital, Wonju, Korea
}

In trauma patients, coagulopathy and abnormal increases or decreases in cell counts are frequently observed, and are associated with high mortality and morbidity in the acute phase of trauma. Because major trauma is often life-threatening, and hematologic abnormalities are multi-factorial and transient, major blood loss is usually suspected to be the primary cause of these abnormalities, and much time and cost may be spent attempting to identify a focus of hemorrhage that might or might not actually exist. Persistent abnormalities in the complete blood count, however, require clinical suspicion of other hematologic diseases to minimize improper transfusions and to improve outcomes, including mortality. Physicians at trauma centers should be familiar with the clinical characteristics of hematologic diseases and should consider these diseases in trauma patients. In this report, we present cases of two hematologic disorders found in trauma patients: autoimmune hemolytic anemia induced by systemic lupus erythematosus and myelodysplastic syndrome.

Keywords: Trauma centers; Hemorrhage; Hematologic diseases

\section{INTRODUCTION}

Complete blood count abnormalities are often present in severely injured patients [1]. Additionally, coagulation defects associated with severe trauma, referred to as trauma-induced coagulopathy, are caused by factors that affect the hematopoietic system and coagulation mechanisms, including massive blood loss, as well as dilutional coagulopathy after transfusion and fluid infusion [1-3]. However, it is difficult to distinguish between hematologic abnormalities associated with trauma and other hematologic disorders because both categories of conditions show similar hematologic abnormalities, and the ability to take a past medical history is limited in trauma patients. (http://creativecommons.org/licenses/by-nc/4.0/) which permits unrestricted noncommercial use, distribution, and reproduction in any medium, provided the original work is properly cited. 
As undiagnosed hematologic disorders in trauma patients could lead to delays in the correct diagnosis and improper treatment, physicians at a trauma center should always consider the possibility of other chronic diseases when encountering atypical and prolonged hematologic dysfunction. We report two rare cases of hematologic diseases diagnosed in patients with serious trauma: systemic lupus erythematosus (SLE)-induced autoimmune hemolytic anemia (AIHA) and myelodysplastic syndrome (MDS).

\section{CASE REPORT}

\section{Case 1}

A 27-year-old male patient with no past medical history

Table 1. Clinical characteristics of the patients at arrival

\begin{tabular}{|c|c|c|}
\hline Variables & Case 1 & Case 2 \\
\hline Sex & Male & Male \\
\hline Age (years) & 29 & 62 \\
\hline Height (cm) & 172 & 158 \\
\hline Weight (kg) & 58 & 52 \\
\hline $\mathrm{sBP} / \mathrm{dBP}(\mathrm{mBP})(\mathrm{mmHg})$ & 107/64 (78.3) & $124 / 82(96.0)$ \\
\hline $\mathrm{HR}$ (/min) & 70 & 64 \\
\hline $\mathrm{RR}(/ \mathrm{min})$ & 20 & 20 \\
\hline $\mathrm{BT}\left({ }^{\circ} \mathrm{C}\right)$ & 34.4 & 34.9 \\
\hline Accident mechanism & Penetrating & Blunt \\
\hline GCS at arrival & 4 & 4 \\
\hline Diagnosis & $\begin{array}{l}\text { Hemoperitoneum } \\
\text { Liver laceration grade III } \\
\text { Jejunum serosal injury }\end{array}$ & $\begin{array}{l}\text { Diffuse axonal injury } \\
\text { Right 2-4th rib fracture } \\
\text { Liver laceration grade II } \\
\text { Multiple facial laceration }\end{array}$ \\
\hline ISS at arrival & 9 & 29 \\
\hline \multicolumn{3}{|l|}{ Initial laboratory findings } \\
\hline $\mathrm{Hb}(\mathrm{g} / \mathrm{dL})$ & 7.9 & 8.6 \\
\hline WBC $\left(10^{9} / L\right)$ & 7.67 & 4.19 \\
\hline $\operatorname{PLT}\left(10^{9} / L\right)$ & 250 & 46 \\
\hline $\mathrm{PT}(\mathrm{s})$ & 13.6 & 11.6 \\
\hline aPTT (s) & 33.2 & 25.1 \\
\hline $\mathrm{FDP}(\mu \mathrm{g} / \mathrm{mL})$ & 1.31 & 45.97 \\
\hline D-dimer & 179 & 7,438 \\
\hline Antithrombin III (\%) & 40 & 80 \\
\hline Fibrinogen (mg/dL) & 195 & 348 \\
\hline $\mathrm{pH}$ & 7.178 & 7.367 \\
\hline Lactate $(\mathrm{mmol} / \mathrm{L})$ & 5.64 & 4.88 \\
\hline Total amount of transfusion (mL) & 6,080 (pRBC 4,480, FFP 1,600) & 27,520 (pRBC 5,280, FFP 4,320, PC 17,920) \\
\hline
\end{tabular}

aPTT: activated thromboplastin time, BP: blood pressure, dBP: diastolic blood pressure, sBP: systolic blood pressure, FDP: fibrinogen degradation product, FFP: fresh frozen plasma, GCS: Glasgow Coma Scale, Hb: hemoglobin, HR: heart rate, ISS: Injury Severity Score, mBP: mean blood pressure, PLT: platelet count, PT: prothrombin time, pH: hydrogen ion concentration, PRBC: packed red blood cell, PC: platelet concentrate, RR: respiratory rate, WBC: white blood cell count. 
was transferred to Yonsei University Wonju Severance Christian Hospital with an upper abdominal stab wound inflicted during a quarrel. At admission, his blood pressure $(\mathrm{BP})$ was $107 / 64 \mathrm{mmHg}$, his heart rate $(\mathrm{HR})$ was 70 beats/min, his body temperature (BT) was $34.4^{\circ} \mathrm{C}$, and he was in a stupor. The stab wound measured approximately $4 \mathrm{~cm}$ and a large amount of blood was found in the wound (Table 1). The initial hemoglobin ( $\mathrm{Hb})$ level was $7.9 \mathrm{~g} / \mathrm{dL}$ (normal range, $13.5-17.0 \mathrm{~g} / \mathrm{dL}$ ), the prothrombin time was $13.6 \mathrm{~s}$ (normal range, 10.6-13.1 s), the activated partial thromboplastin time was $33.2 \mathrm{~s}$ (normal range, 23.6-30.9 s), the fibrinogen level was $195 \mathrm{mg} / \mathrm{dL}$ (normal range, $200-400 \mathrm{mg} / \mathrm{dL}$ ), and the lactate dehydrogenase (LDH) level was 169 U/L (normal range, <280 U/L). Fifteen minutes after the patient arrived at Yonsei University Wonju Severance Christian Hospital, he was taken to the


operating room and underwent exploratory laparotomy. The surgical findings revealed a liver laceration in segment 3 with hemoperitoneum and a serosal tear of the jejunum. Bleeder ligation of the liver and serosal repair of the jejunum were performed, after which two Jackson-Pratt drains were placed in the abdominal cavity. During the operation, two packs of red blood cells (RBCs) and two packs of fresh frozen plasma were transfused and $6 \mathrm{~L}$ of crystalloid fluid was infused. The patient received ABO-compatible transfusions and the antibody screening test was negative.

After the operation, the $\mathrm{Hb}$ level remained near $9.0 \mathrm{~g} / \mathrm{dL}$ until postoperative day (POD) 10, but suddenly decreased to $6.6 \mathrm{~g} / \mathrm{dL}$. The haptoglobin level also decreased to $2 \mathrm{mg} / \mathrm{dL}$ (normal range, $26-185 \mathrm{mg} / \mathrm{dL}$ ), whereas the white blood cell (WBC) count increased to $26.05 \times 10^{9} / \mathrm{L}$
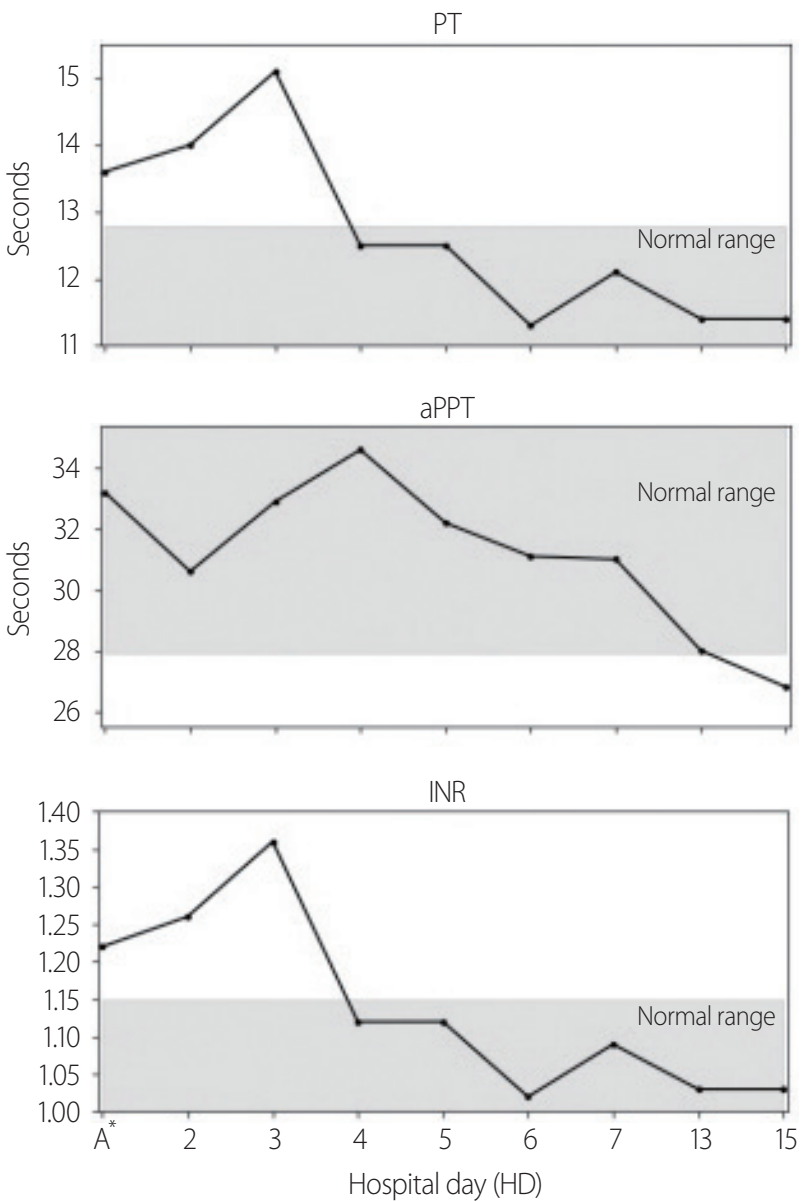

Fig. 1. Changes in laboratory findings over time in (A) case 1 and (B) case 2 . The normal range is indicated by the gray square. $A^{*}$ : admission day, aPTT: activated partial thromboplastin time, INR: international normalized ratio, Hb: hemoglobin, WBC: white blood cell, PLT: platelet, PT: prothrombin time. 
(normal range, $[4-9] \times 10^{9} / \mathrm{L}$ ), the platelet (PLT) count increased to $837 \times 10^{9} / \mathrm{L}$ (normal range, $[165-360] \times 10^{9} / \mathrm{L}$ ) (Fig. 1A), and the LDH level to 1,954 U/L. The creatinine level remained within the normal range $(<1.4 \mathrm{mg} / \mathrm{dL})$ until POD 9, but suddenly increased to $1.97 \mathrm{mg} / \mathrm{dL}$. No active hemorrhage was found in the drain or on abdominal computed tomography (CT). Hemolytic anemia was suspected because the patient's hemolytic score [4] was 6 , the hemolysis index [5] was 4 , and hyperbilirubinemia was observed starting on POD 9. The patient was positive for direct antiglobulin immunoglobulin $\mathrm{G}$ (IgG). The osmotic fragility of RBCs was increased, the immature reticulocyte fraction was $42.44 \%$ (normal range, $2-13 \%$ ), the reticulocyte fraction was $8.13 \%$ (normal range, $0.5-1.5 \%$ ), and the reticulocyte hemoglobin content was $30.9 \mathrm{pg}$ (normal range, 25-30 pg) [6]. On the basis of these
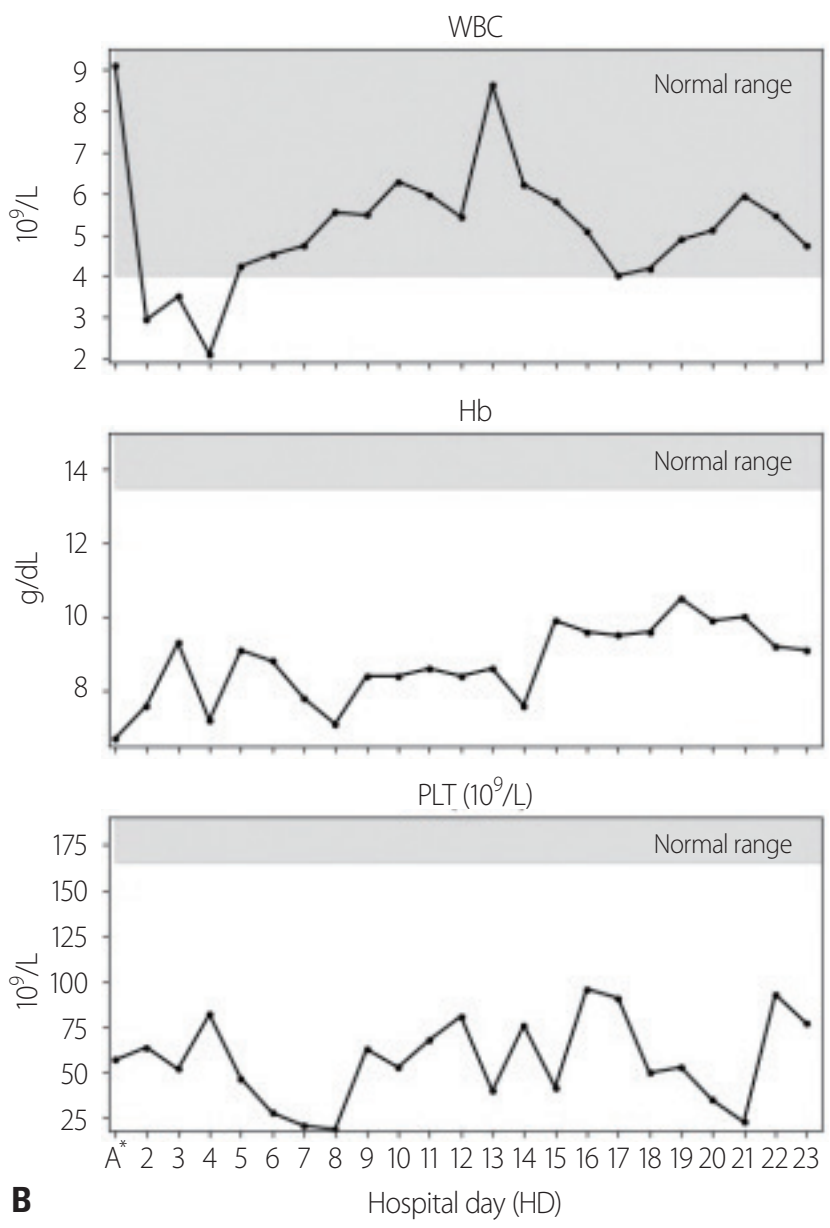

Fig. 1. Continued findings, we diagnosed AIHA and conducted additional complement and antibody tests to evaluate the reason for AIHA. Anti-Smith antibody, anti-ribonucleoprotein antibody, anti-nuclear antibody, and anti-cardiolipin IgG were positive. Finally, under the diagnosis of AIHA with SLE according to the 2019 European League Against Rheumatism and American College of Rheumatology (EULAR/ACR) classification criteria (Table 2), $0.5 \mathrm{mg} / \mathrm{kg}$ of prednisolone was maintained for 11 days, and the patient was discharged with a $\mathrm{Hb}$ level of $11.6 \mathrm{~g} / \mathrm{dL}$.

\section{Case 2}

A 62-year-old male patient with no past medical history was transferred to Yonsei University Wonju Severance Christian Hospital. The patient was traumatized while his head was sucked in a conveyor belt while working at
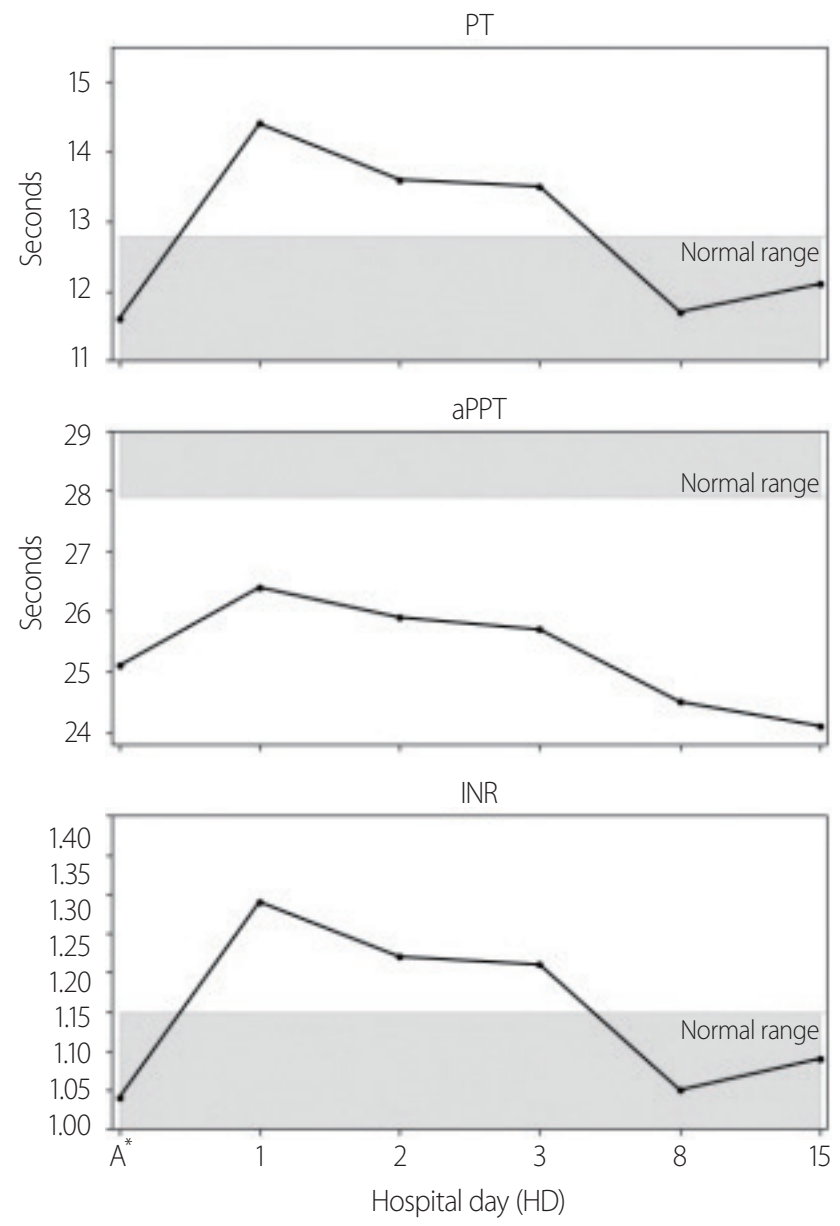
a nearby factory. His BP was $124 / 82 \mathrm{mmHg}$, his HR was 64 beats $/ \mathrm{min}$, and his $\mathrm{BT}$ was $34.9^{\circ} \mathrm{C}$. He was semicomatose upon arrival (Table 1) and diffuse axonal injury was suspected based on brain CT. On abdominopelvic $\mathrm{CT}$, a grade II liver laceration was observed in segments 4 and 5, and blunt trauma of the duodenum was suspected (Fig. 2). In addition, chest CT showed fractures of the left second to eighth ribs and the left scapula, as well scant hemothorax in the left thoracic cavity. The patient was admitted to the intensive care unit following intubation, and angiography of the superior mesenteric artery and celiac trunk was performed to check for additional intraperitoneal bleeding. Additionally, esophagogastroduodenoscopy was performed to confirm the presence

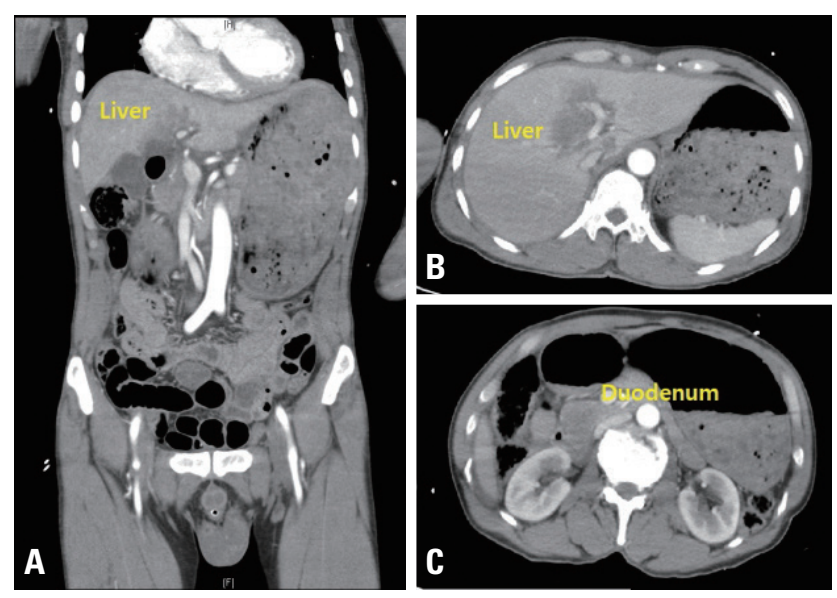

Fig. 2. (A, B) Grade II liver laceration in liver segments 4 and 5, (C) thickened duodenal wall, reflecting a duodenal blunt injury.

Table 2. The 2019 EULAR and ACR classification criteria for systemic lupus erythematosus

\begin{tabular}{|c|c|c|c|}
\hline Domains & Criteria & Weight & Patient $^{\mathrm{a}}$ \\
\hline Constitutional & Fever & 2 & Positive \\
\hline Hematologic & $\begin{array}{l}\text { Leukopenia } \\
\text { Thrombocytopenia } \\
\text { Autoimmune hemolysis }\end{array}$ & $\begin{array}{l}3 \\
4 \\
4\end{array}$ & $\begin{array}{l}\text { Positive } \\
\text { Positive } \\
\text { Positive }\end{array}$ \\
\hline Neuropsychiatric & $\begin{array}{l}\text { Delirium } \\
\text { Psychosis } \\
\text { Seizure }\end{array}$ & $\begin{array}{l}2 \\
3 \\
5\end{array}$ & \\
\hline Mucocutaneous & $\begin{array}{l}\text { Non-scarring alopecia } \\
\text { Oral ulcers } \\
\text { Subacute cutaneous or discoid lupus } \\
\text { Acute cutaneous lupus }\end{array}$ & $\begin{array}{l}2 \\
2 \\
4 \\
6\end{array}$ & \\
\hline Serosal & $\begin{array}{l}\text { Pleural or pericardial effusion } \\
\text { Acute pericarditis }\end{array}$ & $\begin{array}{l}5 \\
6\end{array}$ & \\
\hline Musculoskeletal & Joint involvement & 6 & \\
\hline Renal & $\begin{array}{l}\text { Proteinuria }>0.5 \mathrm{~g} / 24 \mathrm{hr} \\
\text { Renal biopsy Class II or V lupus nephritis } \\
\text { Renal biopsy Class III or IV lupus nephritis }\end{array}$ & $\begin{array}{c}4 \\
8 \\
10\end{array}$ & \\
\hline Antiphospholipid Ab & $\begin{array}{l}\text { Anti-cardiolipin Ab or } \\
\text { Anti- } \beta_{2} G P 1 \text { Ab or } \\
\text { Lupus anticoagulant }\end{array}$ & 2 & Positive \\
\hline Complement protein & $\begin{array}{l}\text { Low C3 or low C4 } \\
\text { Low C3 and low C4 }\end{array}$ & $\begin{array}{l}3 \\
4\end{array}$ & \\
\hline SLE-specific Ab & $\begin{array}{l}\text { Anti-dsDNA Ab or } \\
\text { Anti-Sm Ab }\end{array}$ & 6 & Positive \\
\hline
\end{tabular}

EULAR: European League Against Rheumatism, ACR: American College of Rheumatology, Ab: antibodies, SLE: systemic lupus erythematosus, hr: hour, Anti- $\beta_{2}$ GP1 Ab: anti- $\beta_{2}$-glycoprotein I, Anti-dsDNA ab: anti-double- stranded DNA, Anti-Sm Ab: anti-Smith antibodies.

The EULAR/ACR score of the case 1 patient was 21. SLE can be diagnosed above EULAR/ACR score 10. 
or absence of a duodenal injury. No abnormalities were found on either test and he received conservative treatment. At the time of admission, his WBC count was $4.19 \times 10^{9} / \mathrm{L}$, his $\mathrm{RBC}$ count was $2.66 \times 10^{12} / \mathrm{L}$ (normal range, $\left.[4.2-5.7] \times 10^{12} / \mathrm{L}\right)$, and his PLT count was $46 \times 10^{9} / \mathrm{L}$. The absolute reticulocyte count (ARC) was $100.6 \times 10^{9} / \mathrm{L}$ (normal range, [29-69] $\times 10^{9} / \mathrm{L}$ ). Pancytopenia persisted after hospitalization and did not improve following repeated transfusions (Fig. 1B). To identify internal bleeding, abdominal and chest CT were performed on hospital day (HD) 8 , but there was no bleeding focus. The WBC count was within the normal range on most days during hospitalization (Fig. 1B). However, since the patient was hospitalized with injuries involving multiple body regions, a fever persisted, and the delta neutrophil index was consistently high, the WBC count was considered to be lower than expected. A peripheral blood smear, serum chemistry tests, autoimmune antibody testing, and viral markers also showed no abnormal findings other than pancytopenia. Therefore, we performed a bone marrow biopsy to make an accurate diagnosis on HD 19, and MDS was eventually diagnosed (Fig. 3A). The karyotype of the patient was $47, \mathrm{XY}+1, \mathrm{t}(1 ; 8)(\mathrm{q} 10 ; \mathrm{q} 10)$, $\operatorname{der}(1 ; 8)$ (q10;q10) (Fig. 3B), the International Scoring System for Evaluating Prognosis in Myelodysplastic Syndromes score was 1.5 (intermediate-2 risk), and his score using the World Health Organization classification-based prognos- tic scoring system was 3 (high risk) [4,7]. After conservative treatment for trauma was completed, the patient was transferred to another hospital on HD 48 according to his wishes.

\section{DISCUSSION}

Coagulopathy and abnormal increases or decreases in cell counts are common in trauma patients [8]. Severe trauma is implicated in bone marrow dysfunction in many cases [9]. Although hematologic abnormalities are related to poor outcomes [10], many physicians at trauma centers rarely consider the possibility of other diseases that can cause hematologic abnormalities in trauma patients with cytopenia or coagulopathy. It is difficult to suspect the possibility of hematologic diseases in the early stage of severe trauma, because most patients are hemodynamically unstable and have coagulopathy. Moreover, the association between hematologic diseases and trauma is not fully understood. Underlying hematologic disorders are usually diagnosed if the laboratory findings are constantly abnormal after a patient stabilizes and there is no obvious bleeding on imaging tests.

In this patient with AIHA, although there was no active bleeding and the patient was in a stable condition, his anemia suddenly worsened on HD 9. We suspected the
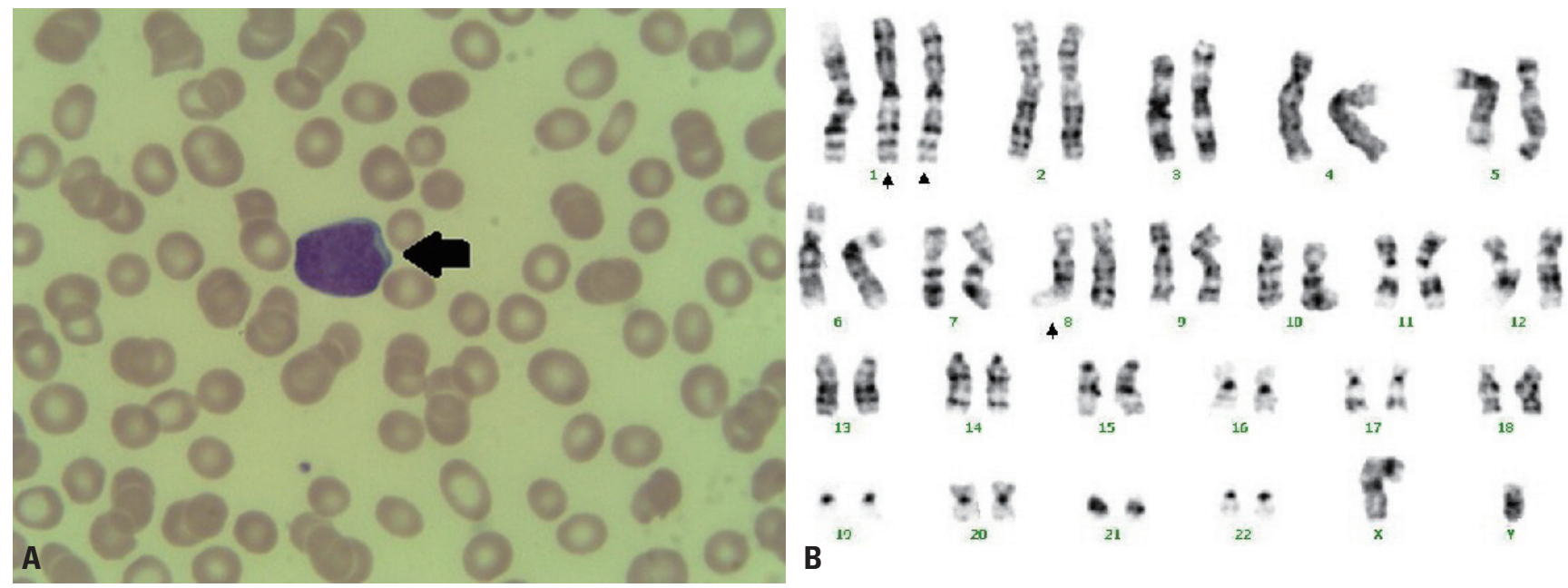

Fig. 3. (A) Representative image of bone marrow biopsy. The arrow indicates a blast cell. (B) Karyotype of bone marrow cells showing 47, XY+1, $t(1 ; 8)$ (q10;q10), der(1;8)(q10;q10). Arrows indicate chromosomal abnormalities. 
possibility of hemolysis based on a high hemolytic score and hemolysis index $[4,5]$, an increased LDH level, and a decreased haptoglobin level. We diagnosed AIHA based on aforementioned findings, a positive direct antiglobulin test, and reticulocytosis. SLE was not considered at first, because the patient did not complain of the typical symptoms of SLE and he presented with leukocytosis and thrombocytosis. However, the antinuclear antibody titer was above 1:80 and the EULAR/ACR score exceeded 10; therefore, despite the patient's lack of clinical symptoms, SLE was diagnosed [11].

MDS is characterized by ineffective hematopoiesis, which in turn results in peripheral blood cytopenia and bone marrow dysplasia. The normal response to anemia, such as an increase in the production of reticulocytes, is poor in patients with MDS. To identify the causes of pancytopenia, drugs that could cause cytopenia were discontinued, and diseases such as sepsis were excluded. However, unexplained pancytopenia persisted for more than 2 weeks, and the patient underwent bone marrow biopsy $[12,13]$. The reason for the increase in ARC even though the patient's underlying disease was MDS was hematopoietic pumping caused by traumatic hemorrhage [14].

Diverse factors lead to delays in the correct diagnosis of underlying hematologic diseases in the early phase of trauma. Therefore, physicians at trauma centers should be familiar with the clinical characteristics of hematologic diseases and take into account the possibility of these diseases in trauma patients to reduce unnecessary treatment and to improve patients' outcomes.

\section{REFERENCES}

1. Gando S, Hayakawa M. Pathophysiology of trauma-induced coagulopathy and management of critical bleeding requiring massive transfusion. Semin Thromb Hemost 2016;42:155-65.

2. Cap A, Hunt B. Acute traumatic coagulopathy. Curr Opin Crit Care 2014;20:638-45.

3. Gando S, Wada H, Thachil J; Scientific and Standardization Committee on DIC of the International Society on Thrombosis and Haemostasis (ISTH). Differentiating disseminated intra- vascular coagulation (DIC) with the fibrinolytic phenotype from coagulopathy of trauma and acute coagulopathy of trauma-shock (COT/ACOTS). J Thromb Haemost 2013;11:826-35.

4. Yoo G, Kim J, Uh Y, Yoon KR, Park SD, Yoon KJ. Scoring system for detecting spurious hemolysis in anticoagulated blood specimens. Ann Lab Med 2015;35:341-7.

5. Lippi G, Favaloro EJ, Franchini M. Haemolysis index for the screening of intravascular haemolysis: a novel diagnostic opportunity? Blood Transfus 2018;16:433-7.

6. Gehrs BC, Friedberg RC. Autoimmune hemolytic anemia. Am J Hematol 2002;69:258-71.

7. Della Porta MG, Tuechler H, Malcovati L, Schanz J, Sanz G, Garcia-Manero G, et al. Validation of WHO classification-based Prognostic Scoring System (WPSS) for myelodysplastic syndromes and comparison with the revised International Prognostic Scoring System (IPSS-R). A study of the International Working Group for Prognosis in Myelodysplasia (IWG-PM). Leukemia 2015;29:1502-13.

8. Corbett JM, Ho KM, Honeybul S. Prognostic significance of abnormal hematological parameters in severe traumatic brain injury requiring decompressive craniectomy. J Neurosurg 2019;132:545-51.

9. Kumar M, Bhoi S, Subramanian A, Kamal VK, Mohanty S, Rao $\mathrm{DN}$, et al. Evaluation of circulating haematopoietic progenitor cells in patients with trauma haemorrhagic shock and its correlation with outcomes. Int J Crit Illn Inj Sci 2016;6:56-60.

10. The Lancet Haematology. The global burden of haematological diseases. Lancet Haematol 2018;5:e1.

11. Fanouriakis A, Kostopoulou M, Alunno A, Aringer M, Bajema I, Boletis JN, et al. 2019 update of the EULAR recommendations for the management of systemic lupus erythematosus. Ann Rheum Dis 2019;78:736-45.

12. Weinzierl EP, Arber DA. The differential diagnosis and bone marrow evaluation of new-onset pancytopenia. Am J Clin Pathol 2013;139:9-29.

13. Priya PP, A R S. Role of absolute reticulocyte count in evaluation of pancytopenia-a hospital based study. J Clin Diagn Res 2014;8:FC01-3.

14. Otterman ML, Nijboer JM, van der Horst IC, van Meurs M, ten Duis HJ, Nijsten MW. Reticulocyte counts and their relation to hemoglobin levels in trauma patients. J Trauma 2009;67:121-4. 